\title{
A competitividade entre destinos na era digital: Uma análise do potencial das mídias sociais no incremento da atratividade turística do destino Portugal
}

\section{Destination competitiveness in the digital age: An analysis of the potential of social media to increase tourism attractiveness of the destination Portugal}

\author{
Anderson Leonardo de Castro Seabra (SEABRA, A. L. de C.) ${ }^{*}$
}

RESUMO - As ferramentas baseadas nas mídias digitais se tornaram indispensáveis na promoção turística e nesse cenário em que a competitividade é um imperativo, a Web e as redes sociais são os novos espaços de disputa entre os destinos. Neste trabalho se discute o papel das mídias digitais, em especial as redes sociais, na competitividade dos destinos por meio de uma apreciação das estratégias de promoção de Portugal. É também discutida a mudança provocada pelas redes sociais na maneira de pensar o marketing dos destinos. Por meio de pesquisa bibliográfica e documental, foram confrontados os resultados do destino Portugal com as ações nas redes sociais realizadas no período de 2011 a 2016. Buscou-se uma correspondência entre estratégias com base nas redes sociais e a competitividade. Foi possível afirmar a importância das redes sociais para o marketing de destinos, contudo sem respaldo para confirmar que sejam decisivas para a competitividade ou que haja uma relação explícita de causa e efeito.

Palavras-chaves: Turismo; Competitividade; Destinos; Estratégia; Redes Sociais.

ABSTRACT - The tools based on digital media have become indispensable in tourism promotion and in this scenario where competitiveness is a must, the Web and social networks are the new spaces for competition between destinations. This paper discusses the role of digital media, especially social networks, in the competitiveness of destinations through a succinct appreciation of the promotion strategies of Portugal. Also discussed is the change brought about by social networks in the marketing way of thinking about destinations. Bibliographical and documentary research were conduct, in order to compare the results of the destination Portugal with the actions in Social Media carried out in the period from 2011 to 2016. We sought a correspondence between strategies based on social networks and competitiveness. It was possible to affirm the importance of social networks for the marketing of destinations, however without support to confirm that they are decisive for the competitiveness or that there is an explicit relation of cause and effect.

Key words: Tourism; Competitiveness; Destinations; Strategy; Social Media.

\footnotetext{
* Formação: Graduação em Administração e Comunicação Social (Bacharelado) pela Universidade Federal do Rio Grande do Norte (UFRN), Mestrado em Estudos Urbanos e Regionais pelo PPEUR (UFRN) e Doutorando em Turismo pelo PPGTUR (UFRN). Atividade profissional: Consultor em Gestão de Marketing e Branding. Endereço físico para correspondência: Rua Teatrologo Meira Pires, 2357, Ap. 501, Capim Macio. CEP: 59080-090 - Natal - Rio Grande do Norte/RN - Brasil. E-mail: leonardoseabra@gmail.com
} 


\section{INTRODUÇÃO}

A questão da competitividade no turismo segue pertinente, intensificada ainda mais pelo impacto das inovações tecnológicas e o aumento da mobilidade dos turistas, que possibilitou que competidores em nível global, concorressem com os destinos locais (CROUCH, 2007).

Nesse cenário, o desenvolvimento das tecnologias da informação e da comunicação (TICs), sua aplicação, e, uso, alteraram radicalmente a relação entre os destinos e seus visitantes (KAPLAN; HAENLEIN, 2010), tornando as ferramentas baseadas na Internet indispensáveis na promoção do turismo para o público-alvo desejado (CRUZ; MOTA; PERINOTTO, 2012). Com efeito, as organizações gestoras de destinos com capacidade para gerir informação, aumentam suas chances de obter vantagem competitiva sobre os demais (SILVA; MENDES FILHO, 2016).

As mídias digitais, especialmente as redes sociais, oferecem uma grande variedade de pontos de contato para que os destinos turísticos distribuam informações, desenvolvam sua imagem e marca, e, interajam com o seu público-alvo com o objetivo de envolver e atrair visitantes, com a vantagem de serem ferramentas menos dispendiosas e de altíssimo alcance global (LANGE-FARIA; ELLIOT, 2012; POPESKU, 2014; KIRALOVA; PAVLÍČCKA, 2014). A Turismo de Portugal é um exemplo de organização que lançou estratégias com base nas redes sociais para atrair visitantes. E ao que parece, tem colaborado para posicionar o destino em local de destaque e a torná-lo mais competitivo.

O objetivo principal deste trabalho foi analisar os usos das mídias digitais, especialmente as Redes Sociais, por meio de uma apreciação sucinta da estratégia implementada pela organização promotora do destino Portugal, Turismo de Portugal (TP), para que fosse possível construir hipóteses acerca da contribuição dessas ferramentas no aumento da competitividade de um determinado destino. Foi também discutida a mudança provocada pelas redes sociais na maneira de pensar o marketing dos destinos e a competitividade. 


\section{REFERENCIAL TEÓRICO}

Como referencial teórico elaborou-se dois subtópicos, sendo um deles sobre competitividade de destinos e ou outro sobre as redes sociais como fator de competitividade.

\subsection{COMPETITIVIDADE DE DESTINOS}

A competitividade, em sentido amplo, se apresenta como a busca por superioridade ou desempenho superior em relação a outros concorrentes na mesma indústria ou em relação à média da indústria (BARNEY, 1995; CROUCH; RITCHIE, 1999). Está envolta por certa relatividade - superior em relação a quem? - e multidimensionalidade - quais são os critérios mais importantes? O que está a ser comparado? - (BARNEY, 1995; CROUCH; RITCHIE, 1999). Também pode ser entendida como "a capacidade crescente de gerar negócios lucrativos nas atividades econômicas, de forma sustentável, superior à concorrência" (RUIZ; AKEL; GANDARA, 2015, p. 17).

A vantagem competitiva de um destino turístico por sua vez não é possuidora de definição unanimemente aceita (CROUCH; RITCHIE, 1999), nem há único um método para medi-la. É complexa, combina elementos difíceis de mensurar, e, engloba vantagens comparativas e competitivas (RUIZ; AKEL; GANDARA, 2015). Boa parte dos estudos recentes a aborda como um arranjo de fatores capaz de tornar um destino mais ou menos competitivo, sobretudo países (CROUCH; RITCHIE, 1999; BUHALIS, 2000; GOOROOCHURN; SUGIARTO, 2005; MAZANEC, WOBER; ZINS, 2007).

Para esses modelos a competitividade não é garantida tão só pelos serviços ou atrativos turísticos existentes, está sujeita a uma variedade de forças, influências e eventos; alguns de difícil controle, por pertencerem a diferentes atores (CROUCH, 2007). Fundamentalmente, a competitividade de destinos turísticos está intimamente ligada às noções de concorrência do mercado, portanto pode ser entendida como sendo uma conformação entre as estratégias, interna e externa.

Uma das abordagens mais marcantes para a competitividade de destinos foi sugerida por Crouch e Ritchie (1999), que tem por base os conceitos de vantagem 
competitiva e vantagem comparativa de Barney (1995). Segundo o modelo proposto (1999), a competitividade de um destino turístico resulta da relação entre quatro dimensões (Recursos Centrais e Atrativos, Fatores de Suporte e Recursos, Gestão do Destino e Determinantes Qualificadores) influenciadas por aspectos macro e microambientais. Estaria ainda relacionada à eficiência e à efetividade que seus recursos (humanos, físicos, conhecimento, capital, infraestrutura, recursos culturais, patrimônio histórico e etc.) são usados para gerar desenvolvimento e crescimento no setor turístico.

Crouch e Ritchie (1999) admitem que esse não é um modelo preditivo ou causal, porém ainda conceitual, e, que carece de desenvolvimento para que seja possível sua generalização. Adiante, esse modelo continuou a ser desenvolvido e foi integrada uma quinta dimensão: Políticas e Planejamento, acrescentando outros componentes a análise.

Para Crouch (2007), as fraquezas de um destino por vezes podem ser difíceis de serem compensadas por outro atributo, mesmo assim, este pode ser competitivo se souber desenvolver uma imagem e uma reputação favoráveis (CROUCH, 2007). O mesmo, também acredita que embora os modelos (de competitividade) tenham identificado os atributos atrelados à competitividade, ainda não são capazes de relacionar quais deles são determinantes.

O Comitê de Turismo da Organização para a Cooperação e Desenvolvimento Econômico (OCDE) em 2013 (DUPEYRAS; MACCALLUM, 2013), propôs um quadro de medição de competitividade no qual incluiu uma lista de indicadores para orientar governos na análise da competitividade do turismo. Neste modelo são esboçados indicadores para futuro desenvolvimento, com destaque para as tecnologias digitais, e, é creditado as midias sociais, como YouTube, Twitter, Instagram e Facebook, uma influência significativa na competitividade do turismo.

O relatório da OCDE considera que os países com grande cobertura de conexão de banda larga possuem uma vantagem competitiva que se torna cada vez mais importante, já que as redes sociais e o acesso à Internet assumem um papel proeminente para os promotores, além de gerar consciência sobre os destinos, potencializar o branding, e, influenciar a tomada de decisões e as compras. Por isso defende que os formuladores das políticas nacionais de turismo garantam que a sua presença nesses meios possa ser positiva e usada para promover o destino no mercado, para que contribua para a competitividade global (DUPEYRAS; MACCALLUM, 2013). 
Portanto, é imprescindível que os destinos se coloquem na vanguarda da aplicação das tecnologias para desenvolver uma posição competitiva mais forte (DUPEYRAS; MACCALLUM, 2013).

Uma das abordagens mais abrangentes para a análise da competitividade dos destinos turísticos é o The Travel \& Tourism Competitiveness Index - TTCI - (Índice de Competitividade em Viagens e Turismo), relatório bianual realizado pelo Fórum Econômico Mundial (WEF). Este relatório é uma avaliação dos fatores de atratividade para realização de investimentos ou desenvolvimento negócios no setor em determinado país, além de servir como um meio para medir a sua performance, permitindo a comparação com outros países. O primeiro TTCI foi publicado em 2007 e desde 2015 o TTCI passou a consistir em quatro pilares (ou subíndices) e 14 indicadores.

De acordo com o TTCI em 2017, Portugal ocupava a 14a posição entre 136 países e a $8^{\mathrm{a}}$ posição na Europa entre 48 países (WEF). A considerar os resultados da análise dos relatórios anteriores, 2013 e 2015, Portugal melhorou progressivamente sua posição global e regional, se colocando a frente dos seus concorrentes ${ }^{1}$.

De todos os fatores que são a base para alcançar a vantagem competitiva de acordo com o relatório, um efeito positivo advém de sua oferta de recursos humanos, níveis de sua infraestrura, e, também pelos esforços através de políticas direcionadas ao setor de viagens e turismo, sem deixar de mencionar seus recursos naturais, históricos e culturais. Outros elementos presentes no relatório como o ambiente de negócios e preços ainda são obstáculos na obtenção de uma vantagem competitiva mais efetiva e assim galgar posições mais altas no mercado internacional (WEF, 2017).

\begin{tabular}{|c|c|c|}
\hline INDICADORES X POSIÇÃO GLOBAL & 2015 & 2017 \\
\hline Country Brand Strategy rating & $\# 21$ & $\# 9$ \\
\hline $\begin{array}{l}\text { Effectiveness of marketing and branding } \\
\text { to attract tourist }\end{array}$ & $\# 37$ & $\# 17$ \\
\hline Comprehensiveness of annual $T \& T$ data & \#87 & $\# 75$ \\
\hline $\begin{array}{l}\text { Cultural and entertainment tourism } \\
\text { digital demand }\end{array}$ & $\# 29$ & $\# 23$ \\
\hline Natural tourism digital demand & $\# 11$ & \#13 \\
\hline Mobile network coverage & $\# 65$ & \#46 \\
\hline
\end{tabular}

QUADRO 1 - EVOLUÇÃO DA POSIÇÃO DE PORTUGAL NO RANKING DO TTCI POR INDICADORES

FONTE: Elaborado pelo próprio autor - Adaptado de The Travel \& Tourism Competitiveness Index - TTCI (WEF, 2015; 2017).

\footnotetext{
1 Portugal ocupou a posição \#20 em 2013 e \#15 em 2015 no ranking global, e, \#9 e \#7 respectivamente no ranking regional (WEF, 2013; 2015).
} 
Nota-se com a apreciação do relatório que a evolução da posição de Portugal no ranking global e regional tem sido acompanhada por indicadores que dizem respeito as práticas de Marketing, Branding, e as TICs. Tais dados geram no mínimo perguntas a respeito da suposta relação entre os esforços de marketing digital, o aumento da competitividade do destino e os seus recentes resultados obtidos. Nos indicadores específicos (Quadro 1) que compõem o índice (ICT readiness, Prioritization of Travel \& Tourism, Natural resources and Cultural Resources) estão as pistas que levaram a discussão desse artigo, que apesar das dificuldades e limitações de um destino, uma estratégia bem executada de marketing, centrada no potencial e possibilidades das novas mídias digitais, pode ser determinante para a competitividade.

\subsection{AS REDES SOCIAIS COMO FATOR DE COMPETITIVIDADE}

A Internet não transformou apenas o campo técnico da comunicação, mas toda a sociedade, na medida em que são usadas cada vez mais ferramentas online para realizar transações, conduzir negócios, adquirir informação e se relacionar com a comunidade (CRUZ; MOTA; PERINOTTO, 2012; POPESKU, 2014). No caso do Turismo, um setor que inegavelmente é influenciado pela tecnologia nos mais diversos aspectos (SILVA; MENDES FILHO, 2016), a evolução e ampliação do alcance da Internet, trouxe mudanças drásticas, como por exemplo, na forma como os viajantes buscam as informações, como planejam e reservam viagens, e, a como compartilham as suas experiências (BUHALIS, 2006; COX et al., 2009).

A combinação entre Internet e turismo também fez com que as organizações aperfeiçoassem as suas ações de marketing, especialmente no que diz respeito às atividades de promoção. As estratégias de marketing passaram a ser mensuráveis de forma direta e quase instantânea, assim como a possibilidade de acompanhar o nível de satisfação do cliente, suas dúvidas e sugestões (POPESKU, 2014). E assim, a Internet se tornou um novo campo de batalha para as organizações envolvidas no setor de viagens e turismo, com uma concorrência cada vez mais acentuada.

As Redes sociais, por sua vez, na forma de Mídias Sociais, impactaram a forma como as pessoas e as organizações, se comunicam entre si e com os clientes, ao permitir partilha de informações e a colaboração entre esses atores, além de serem focadas na 
criação de comunidades em torno de tópicos ou áreas de interesses (CRUZ; MOTA, PERINOTTO, 2012). Esse aspecto evidencia a mudança na natureza da comunicação e as noções de comunidade, que impactou, na área de turismo e viagens, as formas como os indivíduos, por exemplo, buscam, coletam e partilham informações, bem como tomam decisões (POPESKU, 2014).

Contudo, devido a vasta quantidade de ofertas online no mercado turístico, a simples presença na web não implica em vantagens competitivas. Os turistas já encontram uma grande variedade de destinos para escolher, porém com menos tempo para tomar uma decisão (KIRALOVA; PAVLÍČEKA, 2014). Dessa forma se tornou uma oportunidade e um desafio para os responsáveis pelas estratégias de marketing dos destinos selecionar as informações mais relevantes e os meios de comunicação mais eficazes, compreendendo assim as motivações que os turistas possuem, visando cativar o cliente (LODA; COLEMN, 2005).

Segundo Kiralova e Pavlíčeka (2014), a diminuição dos orçamentos de marketing também teria sido decisiva para a inovação das estratégias de comunicação e marketing de destinos. As novas mídias digitais oferecem uma abordagem menos dispendiosa para o marketing de destinos, com altíssimo alcance e muitas oportunidades para a atração dos visitantes. Assim, cada vez mais, destinos mudam suas estratégias de uma base tradicional (mídia impressa, TV, outdoors) para a Web e as plataformas de redes sociais (KIRALOVA; PAVLÍČEKA, 2014).

Em paralelo, os visitantes parecem cada vez menos confiar na publicidade centrada nas vantagens e características dos destinos e depositam alto grau de confiança em suas redes sociais - onde a informação é compartilhada por outros viajantes (KIRALOVA; PAVLÍČEKA, 2014). Assim, o conhecimento sobre destino de viagem é adquirido através da interação social (POPESCU; ALECSA, 2015). Diante disso, as mídias sociais se tornaram um canal oportuno, uma vez que, por meio delas, o indivíduo tem acesso a um conjunto de informações (textos, fotografias, vídeos, etc.), gerados por diferentes fontes (Organizações, empresas do setor, locais, turistas, etc.) que compõem a oferta turística de um destino, e em tempo real (HAYS; PAGE; BUHALIS, 2013).

Nesse sentido as Mídias sociais são especialmente importantes para as atividades das organizações responsáveis pela promoção de um destino, podendo ser utilizadas de forma estratégica em diversas ocasiões, antes da viagem (para inspirar, informar, 
participar), durante a viagem (para facilitar, dar suporte, melhorar a experiência) e depois (para compartilhar, envolver e fidelizar) (POPESKU, 2014).

As principais motivações para sua utilização têm sido seus benefícios e a sua eficácia especialmente para: (a) criar/aumentar a conscientização sobre o destino; (b) alcançar publicidade global; (c) incentivar os visitantes a planejar sua viagem; (d) fortalecer a imagem de destino como um destino favorito; (e) visar um novo mercado/ou mercado específico; (f) aumentar o número de visitantes; (g) gerar buzz em torno do destino; (h) mudar a posição do destino na mente dos visitantes (LANGEFARIA; ELLIOT, 2012; KIRALOVA; PAVLÍČEKA, 2014). E para esses objetivos, existem vastas possibilidades de utilizações das redes sociais nas quais as organizações gestoras dos destinos podem desenvolver (KAPLAN; HAENLEIN, 2010; LANGEFARIA; ELLIOT, 2012; JUCAN; JUCAN; ROTARIU, 2013): (i) Construir comunidades de interesse em torno do destino; (ii) Gestão da marca (iii) Gerar conteúdo engajador; (iv) Destacar eventos e campanhas atuais; (v) Ampliar e encorajar as recomendações "boca-a-boca", obtendo assim um "efeito viral"; (vi) Obter feedback.

As Mídias socias, deste modo, são a oportunidade para desenvolver e manter relacionamentos com os clientes (YADAV; ARORA, 2012). Além do mais, servem como uma fonte rica de informação sobre as necessidades, desejos, paixões e até mesmo hábitos de consumo e de compra dos clientes, que podem ser inputs valiosos na elaboração de estratégias competitivas, pois nelas há uma vastidão de conteúdo não estruturado, gerado pelos usuários da rede, que podem ser examinados, selecionados, classificados, monitorados e avaliados (POPESKU, 2014). E isso pode auxiliar no processo de assimilação e desenvolvimento da imagem do destino (MARCHIORI; PAVESE; CANTONI, 2012). Desta forma, acredita-se que as informações disponibilizadas podem influenciar no processo de decisão da escolha do destino.

\section{METODOLOGIA}

Este artigo é resultado de um estudo de caráter exploratório (CRESWELL, 2007), com o propósito de debater a importância das mídias digitais e das redes sociais para a competitividade de um destino, e construir algumas hipóteses. Em termos de 
metodologia, trata-se de uma abordagem qualitativa, constituída por um estudo de caso, que teve como objeto de estudo o destino Portugal, e compreendeu pesquisa bibliográfica e documental (CRESWELL, 2007), e, fontes secundárias.

O estudo bibliográfico foi realizado com uso da técnica de revisão de Literatura, como a análise de publicações que abordassem os temas, sobretudo, sobre o uso de redes sociais para a competividade dos destinos turísticos (POPESCU; ALECSA, 2015; POPESKU, 2014; KIRALOVA; PAVLICEKA, 2014; YADAV; ARORA, 2012). Quanto à análise documental, foi feita através de consulta a documentos oficiais; Plano Estratégico Nacional de Turismo - PENT, documento principal para o turismo em Portugal (TP, 2007; 2013-2015), Plano de Ação para o Desenvolvimento do Turismo em Portugal 2020 (2014), e, com os dados das Estatísticas do Turismo do Instituto Nacional de Estatistica - (INE, 2014; 2015; 2016), Banco de Desenvolvimento de Portugal (BDP) (2016) e Banco Português de Investimento (BPI) (2016) além de depoimentos coletados de entrevistas concedidas por representantes do Turismo de Portugal a veículos de comunicação do país (Publiturius, Público, Expresso), considerados para compreender a evolução e a execução da estratégia do destino.

Do cruzamento dos dados oriundos dos documentos citados (relatórios, entrevistas, planos) foram feitas análises e retiradas algumas conclusões parciais e outros questionamentos. Não se almejou aqui encontrar uma verdade absoluta, mas discutível, o que no fim, resulta em ponto de vista.

\section{DESTINO PORTUGAL: O OBJETO DE ESTUDO}

O Turismo é uma das principais atividades econômicas de Portugal e atravessa uma fase de expansão, sendo responsável por quase $50 \%$ das exportações de serviços e perto de $17 \%$ das exportações totais (INE, 2016). O número de voos e de passageiros duplicou em dez anos, de 2005 a 2015 (BPI, 2016). De acordo com o INE (2016), nesse mesmo intervalo, o país cresceu sempre mais do que os vizinhos, tendo um aumento das receitas de pelo menos o dobro do registrado na Espanha, por exemplo. A balança turística teve um aumento excedente de 2,6\% para 4,3\% do PIB, entre 2010 e 2015. 
Segundo dados do INE (2017), em 2016, Portugal recebeu cerca de 12 milhões de turistas estrangeiros, tendo um crescimento de $11,5 \%$ na atividade em relação ao ano de 2015, que correspondeu pelo peso de $7 \%$ do Turismo no comércio global, $10 \%$ na riqueza gerada globalmente, e, se apresentou como responsável por um emprego em cada 10 em todo o mundo no setor. Ainda apresentou o quinto maior saldo da balança turística na União Europeia, com aumento de 12\% em relação a 2015 (INE, 2017). Neste mesmo ano, Portugal foi o terceiro destino mais buscado no Google de acordo com o relatório Year in Search (GOOGLE, 2016). Por trás desses números e da visibilidade conquistada há uma estratégia planejada fortemente baseada no uso da Web e das Redes Sociais.

Essas estratégias tiveram origem no Plano Estratégico Nacional de Turismo (PENT), o documento principal para o turismo no país (TP, 2007). Juntamente, foi instituído o Turismo de Portugal, I.P. como a entidade responsável pela promoção e valorização e sustentabilidade da atividade turística (TP, 2007).

A Organização Turismo de Portugal (TP) foi estabelecida para realizar atividades de promoção do turismo, coordenação de atividades de organizações de turismo, empresas e outras partes interessadas no turismo em Portugal, que atuassem direta ou indiretamente na promoção do turismo (TP, 2007). Em quase uma década de sua atuação (a partir de 2007), o setor do turismo afirmou-se em definitivo como um dos principais motores da economia portuguesa. A ele se deve grande parte do crescimento econômico alcançado nos últimos dez anos, com sua contribuição alcançando quase 7\% do PIB do país (INE, 2016). Essa história fez-se de vários momentos, os quais nesse artigo buscou-se analisar da perspectiva da contribuição das estratégias de mídias sociais.

\section{DISCUSSÃO: A ESTRATÉGIA DE PORTUGAL NAS REDES SOCIAIS}

Elaborado em 2006, em sua primeira versão o Plano Estratégico Nacional do Turismo (PENT), destacou a necessidade de inovar e de comunicar uma proposta de valor diferenciada, atuando em segmentos alvo por mercado emissor (TP, 2007). A partir dele, a Internet começou a receber maior enfoque na promoção do turismo. 
Os resultados, porém, ficaram aquém do esperado. Entre diversos fatores influentes podem ser citados: a evolução dos canais de informação e distribuição, a proliferação de novos destinos, a mudança dos hábitos de consumo e o comportamento do consumidor/turista na seleção, preparação e realização da sua viagem (TP, 2013). Entre as lições aprendidas, a necessidade de compreender as tecnologias da informação no sentido da modernização empresarial (TP, 2013). Em consequência disso, foram feitas revisões na estratégia, e, sucessivamente foram concebidas ações baseadas no meio digital, como também está explícito no Plano de Ação do Turismo para Portugal 2020, elaborado em 2014.

Com a revisão do PENT em 2013, que tinha como horizonte temporal o período de 2006 a 2015, e a elaboração do Plano de Ação do Turismo para o Desenvolvimento do Turismo em Portugal 2020, que abrange o período de 2014 a 2020, foi dado reconhecimento a crescente importância da Internet como canal de comunicação, informação e comercialização (PENT, 2013). Assim, as plataformas web, redes sociais, dispositivos móveis e conteúdos digitais tiveram seu papel reforçado e privilegiado.

"Nós mudámos muito subitamente o modelo de promoção", explica Adolfo Mesquita Nunes (2017), secretário de Estado do Turismo em Portugal no período entre 2011 e 2015. "É, antes um modelo que vai de encontro às necessidades das empresas, dos empresários, e que pretende beneficiar todos os agentes do setor" (LIMA, 2014), António Pires de Lima, Ministro da Economia de Portugal durante a revisão do PENT.

Segundo João Cotrim de Figueiredo, presidente do Turismo de Portugal entre os anos de 2013 e 2016, “[...], a estratégia passou a ser feita sobretudo através do marketing digital e não institucional, e com impacto em todas as cinco fases do ciclo da viagem (sonho, planejar, reserva, experiência e partilha)" (FIGUEIREDO, 2017).

"O objetivo é estarmos em todos os momentos da viagem: desde que o turista está a sonhar [...]" (MONTEIRO, 2017), assim resume o que almejavam com o plano, a diretora de Apoio à Venda do Turismo de Portugal em 2017, Lídia Monteiro.

Segundo Monteiro (2017) uma das diretrizes mais importantes do plano foi o alinhamento da estratégia de comunicação com as novas tendências. Fora adotado um novo paradigma assentado nas estratégias de new marketing.

Essa estratégia tinha como objetivo induzir a busca proativa das pessoas pelos conteúdos criados, em oposição ao que acontece numa estratégia de marketing 
tradicional em que os conteúdos são 'impostos' ao público (MONTEIRO, 2017). Assim, a partir de 2013, todo orçamento do TP foi destinado a campanhas internacionais exclusivamente em plataformas digitais, colocando fim aos outdoors, anúncios na televisão e nos jornais, panfletos e outras mídias off-line.

Nos primeiros anos desta década, a preponderância dos meios digitais suplantou a dos meios tradicionais e a transformação tornou-se inevitável [...] Fizemos um trabalho interno de definição de uma nova estratégia de comunicação [...] Trabalhamos para pôr Portugal no mapa [...] Nos dias que correm, pôr Portugal no mapa é pô-lo onde está toda a gente, na Internet e nas redes sociais. (MONTEIRO, 2017).

Para António Pires de Lima (2014) esta era uma forma de "promover Portugal com menos recursos, mas de uma forma mais eficaz". Ainda sobre a questão orçamentária que impôs a busca por uma estratégica eficaz com menos recursos, explicou (LIMA, 2014):

Estamos confrontados com uma diminuição de cerca de $30 \%$ das verbas alocadas ao Turismo de Portugal para promoção turística, ainda assim têm-se conseguido os resultados que foram apresentados. [...] creio que é importante sublinhar aquilo que é a estratégia de focalização dos recursos nas ferramentas consideradas mais adequadas e depois explicar como é que estas ferramentas, que passam pela utilização da tecnologia e por um relacionamento direto dos clientes, podem e devem ser utilizadas.

Esse redirecionamento não somente visava a redução de custos, mas conscientemente uma busca por estratégias eficazes para conquistar maior fatia do mercado: "Para se continuar a ganhar quota de mercado é importante ter um acesso direto com os nossos potenciais clientes" (LIMA, 2014). "Não havia dinheiro para fazer as duas coisas. [...] E para quê gastar recursos em grandes cartazes e brochuras se a Internet era 'muito mais eficaz' para chegar exatamente a quem se queria?" complementa Nunes (2017). E assim, as possibilidades de segmentação do mercado, e a presença em todas as etapas do processo de viagem através da Internet, fez com que aumentasse o potencial da estratégia.

Deste modo, foi feita redistribuição do investimento em promoção por mercado e produto, adequando recursos (1) ao potencial de crescimento identificado e (2) ao retorno do investimento promocional; adequação da variedade de instrumentos de promoção à capacidade de conhecimento dos critérios de decisão do consumidor, assim 
como ao conhecimento sistematizado das diversas tipologias de segmentação (por mercado, motivação, produto ou subproduto) (TP, 2013).

Essa abordagem motivada pelos benefícios das mídias digitais (MARCHIORI; PAVESE; CANTONI, 2012; LANGE-FARIA; ELLIOT, 2012; JUCAN; JUCAN; ROTARIU, 2013; KIRALOVA; PAVLÍČEKA, 2014), em particular as redes sociais, se desdobrou em uma série de ações possibilitadas por essas ferramentas (JUCAN; JUCAN; ROTARIU, 2013; POPESKU, 2014): Desenvolvida a presença multicanal integrada das ofertas do destino (portais, plataformas móveis, redes sociais) e estimulada venda pelos canais online; Capacitados os portais de destino com estratégias de comunicação e funcionalidades alinhadas com as tendências mais atuais e inovadoras de interação e envolvimento com o turista; As ações de comunicação foram dirigidas em função dos segmentos-alvo identificados (por mercado emissor, por motivação primária, por demografia, por etapa do processo de compra); Fomentada a interação com o turista, através de uma gestão ativa de comunidades virtuais e a presença nas principais redes sociais, introduzindo uma filosofia participativa, colaborativa e de cocriação por parte dos turistas; Reforçada a disseminação de conteúdos digitais personalizados e ricos em conteúdo de entretenimento (aplicativos, vídeos, jogos etc.); Desenvolvidas campanhas baseadas em conteúdos e narrativas relevantes para o perfil de turista de cada segmento e mercado emissor, através de meios que propiciavam interatividade e a partilha com as pessoas (TP, 2013, 2014).

"Mas só se aposta naquilo em que Portugal é ou tem condições para se tornar número 1" afirmou Figueiredo (2017). Os conteúdos de comunicação foram ancorados, por um lado, em aspectos distintivos da oferta turística portuguesa, que representavam grande capacidade para mobilizar e motivar uma viagem, como o surf, esportes náuticos, o golfe, a gastronomia, a cultura ou a música, por outro baseado em experiências e emoção.

Foram criados sistemas de gestão de relacionamento com o cliente (CRM Customer Relationship Management) e implantadas ferramentas de análises do comportamento e das tendências do consumidor usuário da internet. Portugal passou a monitorar as pesquisas que os estrangeiros faziam sobre o país, a partir do IP dos seus computadores: 
Sabíamos quando as pessoas estavam quase a decidir o destino de férias porque o padrão de visitas a sites é diferente em relação a quando se está à procura. E 48 a 72 horas antes da decisão conseguíamos mandar outra mensagem mais incisiva. Se fosse uma sueca de 35 anos, golfista, por exemplo, fazíamos com que aparecesse no seu Facebook e no site que estava a consultar umas imagens fantásticas de mulheres a jogar golfe em Portugal, que pareciam mesmo feitas à sua medida. Isso pode fazer a diferença (FIGUEIREDO, 2017).

Isso permitiu uma visão única sobre o público, e assim responder às suas necessidades e potencializar a atração e fidelização e, rastrear os resultados do investido através de métricas do marketing digital, imprescindíveis para a gestão desse tipo de estratégia (MARCHIORI; PAVESE; CANTONI, 2012; LANGE-FARIAELLIOT, 2012; POPESKU, 2014).

Também foram contratados especialistas em otimização de motor de buscas com a missão de assegurar que as principais atrações de Portugal estariam em posição privilegiada nas pesquisas sempre que um indivíduo buscasse informações sobre viagens.

\footnotetext{
Quando os dinamarqueses, suecos e finlandeses, começam a pesquisar por férias em janeiro, o Facebook deles enche-se de vídeos e referências a Portugal - como a imagem da Lagoa do Fogo, nos Açores, com a legenda "Nem todos os spa têm quatro paredes". Quando um francês pesquisa "surf" no Google, os resultados que aparecem primeiro são relativos a Peniche, à Ericeira, à Costa Vicentina" (MONTEIRO, 2017).
}

Para esse efeito, mais da metade do orçamento do Turismo de Portugal destinado a promoção foi direcionada ao Google, para a compra de palavras-chave: "Tornámo-nos o maior cliente da Google em Portugal" [...] "E para o Facebook seguia outra fatia de 25\% das verbas", contou Figueiredo (2017).

Graças a esforços de inteligência como esses e a partir da compreensão dos dados gerados, foi possível desenvolver propostas e realizar a promoção do destino "sob medida". Cada segmento era objeto de comunicação específica, portanto, os conteúdos e narrativas foram adaptados de forma que fossem relevantes para cada um, valendo-se da possibilidade de customização para atrair cada grupo específico de acordo com suas características, como sugerem Loda e Colemn (2005).

O caso do Surf para ser um exemplo. Como explicou Figueiredo (2017), mais que o número de pessoas atraídas pelo esporte, era a imagem associada ao surf que interessava explorar para a promoção do país. Para isso, fizeram análises semânticas e 
de conteúdo em relação ao que era postado sobre Portugal nas redes sociais e em sites como Tripadvisor. Analisadas milhares de postagens, foi possível captar as expressões que mais se associavam a Portugal. Encontradas as expressões que mais se repetiam, maioria em referência a "Se sentir em casa", foi elaborada uma campanha centrada nessa percepção (FIGUEIREDO, 2017):

O espírito de comunidade, partilha, liberdade, descontração e juventude associados ao surf encaixavam nessa ideia. Foi à boleia daquela expressão que se desenhou todo um plano de marketing para apresentar o país como um destino caloroso, afetivo, quentinho, onde todos se sentissem em casa.

Outro exemplo desta nova abordagem, mais próxima do consumidor foi a campanha realizada em 2013 denominada "Be our guest" (IMAGEM 1), centrada nos visitantes (TP, 2014). Esta estratégia de promoção para 2013 acompanhava as tendências de consumo dos turistas que escolhem o destino Portugal, influenciados pela internet e recomendação de familiares e amigos.

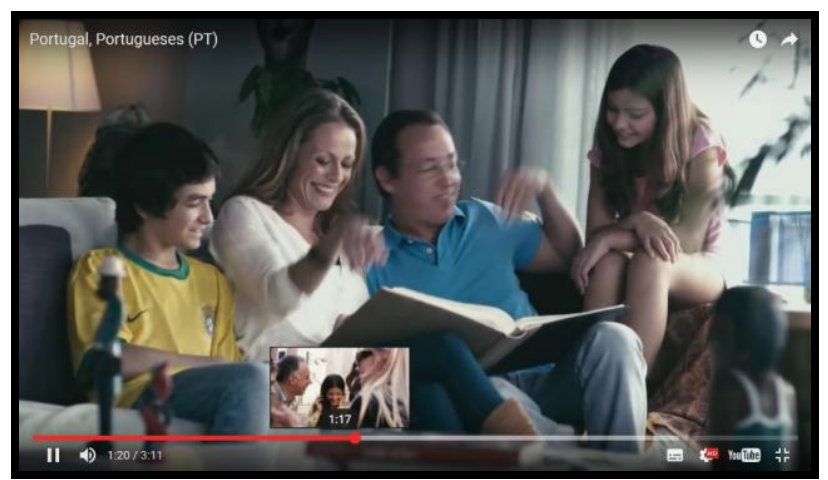

IMAGEM 1 - FILMES DA CAMPANHA “BE OUR GUEST” MOBILIZARAM TURISTAS FONTE: Youtube (2013).

Em vídeos divulgados no Youtube e nas Redes Sociais, visitantes de diferentes nacionalidades e idiomas, compartilhavam suas experiências e memórias sobre sua passagem pelo destino. A mensagem podia ser compartilhada e difundida pelas redes sociais. A campanha contemplava ainda ações que estimulavam a interação com o turista, em que eram convidados a testemunhar no Facebook da Turismo de Portugal a sua experiência no país. Os turistas com as experiências mais votadas pelos outros seguidores tinham a oportunidade de retornar a Portugal gratuitamente. A campanha incluiu ainda a criação de plataformas específicas para diferentes públicos, segmentadas 
de acordo com os produtos turísticos que privilegiavam no destino, como city breaks, natureza, surf, golfe ou turismo religioso.

Em 2014, "Be our guest" foi substituída pela "Visit Portugal and Share it" (IMAGEM 2) que direcionaria esforços ainda maiores para o poder de interação e engajador das redes sociais, com o incentivo ao uso da hashtagh \#eyesofportugal que por sua vez compartilhavam as fotos dos usuários/visitantes nos canais oficiais do destino, fortalecendo o relacionamento com eles e da marca (TP, 2014).

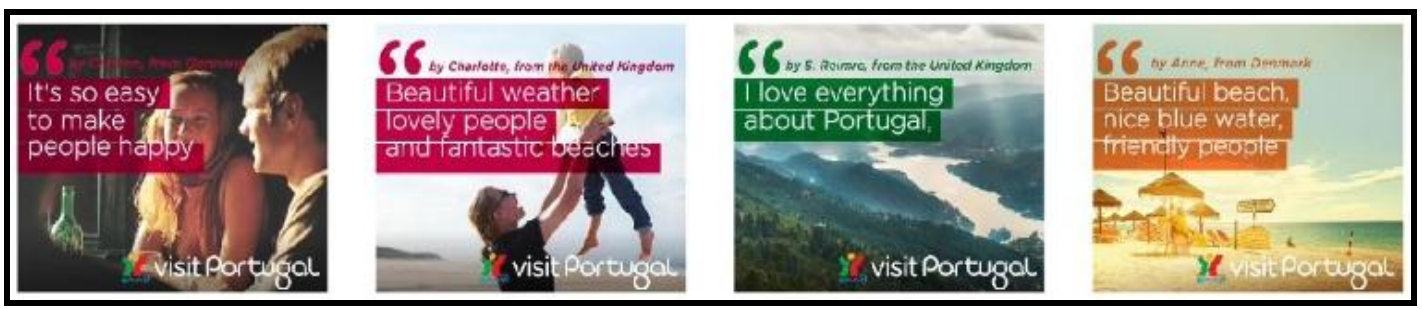

IMAGEM 2 - CAMPANHA "VISIT PORTUGAL AND SHARE IT"

FONTE: (TP, 2014).

A campanha "Visit Portugal and Share it" (IMAGEM 3), utilizando o poder das redes de mobilização, engajamento, desenvolvimento de relacionamento e fortalecimento da marca, encorajava os visitantes a compartilhar as fotos de sua experiência no país para um concurso na qual seriam divulgadas as mais "curtidas".

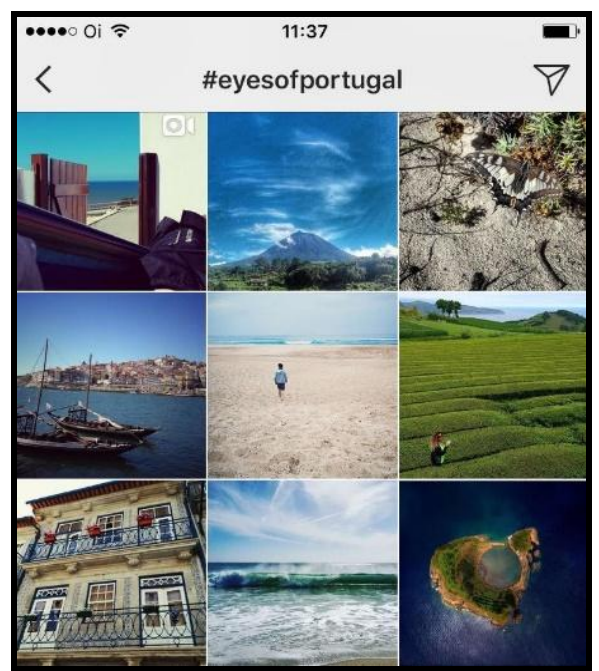

IMAGEM 3 - CAMPANHA "VISIT PORTUGAL AND SHARE IT": FOTOS COM A TAG (HASHTAG) \#EYESOFPORTUGAL PUBLICADAS PELOS VISITANTES.

FONTE: (TP, 2014).

Estas estratégias de promoção iniciadas em 2013 acompanharam as novas tendências de consumo dos turistas que escolhiam o Destino Portugal, influenciados 
pela internet e recomendação de familiares e amigos. Foi percebido que era através da internet que cada vez mais se escolhiam os destinos, reservavam voos e acomodação, sem intermediários e à medida dos interesses de cada um (COX et al. 2009; LANGEFARIA; ELLIOT, 2012; HAYS; PAGE; BUHALIS, 2013; KIRALOVA; PAVLÍČEKA, 2014; POPESCU; ALECSA 2015). Ao todo foram realizadas mais de 400 campanhas exclusivamente online para 13 mercados-alvo (TP, 2014).

As mídias sociais podem de fato ajudar os destinos a permanecerem competitivos se apresentarem conteúdo interessante, usarem criatividade, derem suporte e motivarem uma comunicação interativa, como defendem Kiralova e Pavlíčeka (2014). Essa estratégia então depende da produção de conteúdos baseados em recursos audiovisuais, narrativas envolventes, interatividades etc., orientados para a internet e os dispositivos móveis. A ausência de competências e recursos internos à época para trabalhar estes novos conteúdos oportunizou no caso de Portugal o surgimento de serviços especializados em marketing digital e produção audiovisual, orientados para a atividade turística (TP, 2014), como por exemplo, o desenvolvimento do App Visit Portugal (IMAGEM 4), para fornecer informações e serviços para auxiliar os visitantes a planejar suas viagens, buscar produtos e serviços, melhorar sua experiência. Informação sobre alojamento, empresas de serviços turísticos, campos de golfe, museus, monumentos e sítios, praias, áreas protegidas, contatos úteis, entre muitos outros. Esse processo foi crucial para a implantação dessas estratégias em busca do desenvolvimento e crescimento do turismo em Portugal, e, consequentemente elevar sua competitividade.

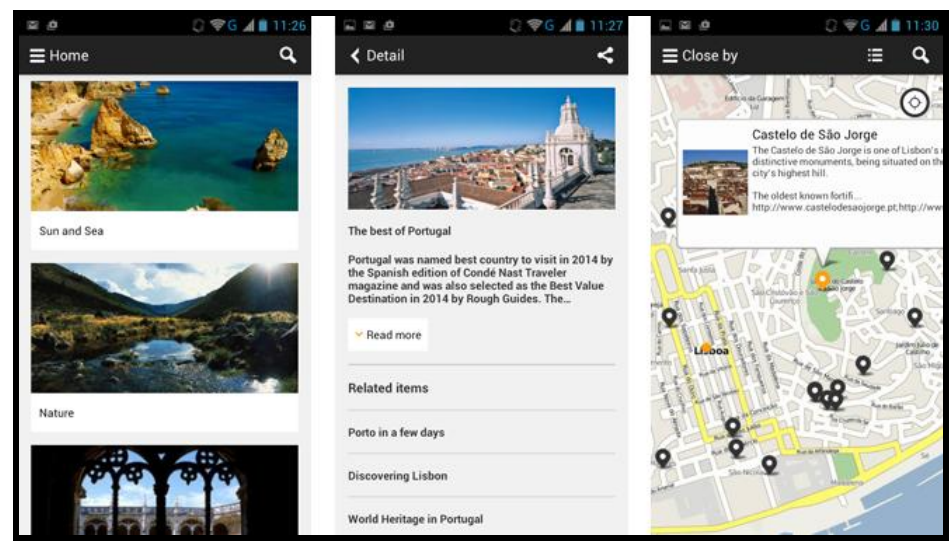

IMAGEM 4 - APP VISIT PORTUGAL

FONTE: Visitportugal.com (2017). 
Ao que parece, uma das principais razões para a aposta no digital foi a restrição orçamentária, que oportunizou o direcionamento ainda maior de recursos para o reforço da presença do destino e seus produtos turísticos nos distintos canais online e no desenvolvimento de estratégias de marketing digital que potencializassem a comunicação e a distribuição da sua oferta, com baixo custo (BUHALIS, 2006; POPESKU, 2014; KIRALOVA; PAVLÍČEKA, 2014). Com os recursos financeiros inteiramente canalizados para o marketing digital, as redes sociais passaram a ser tão importantes quanto a presença em feiras de turismo. Resultado desses esforços junto as redes sociais, a página Visitportugal no Facebook (IMAGEM 5) registrou em 2013 mais de 114 mil fãs, posicionando-se assim entre os destinos turísticos europeus com mais seguidores nesta rede social (TP, 2013).

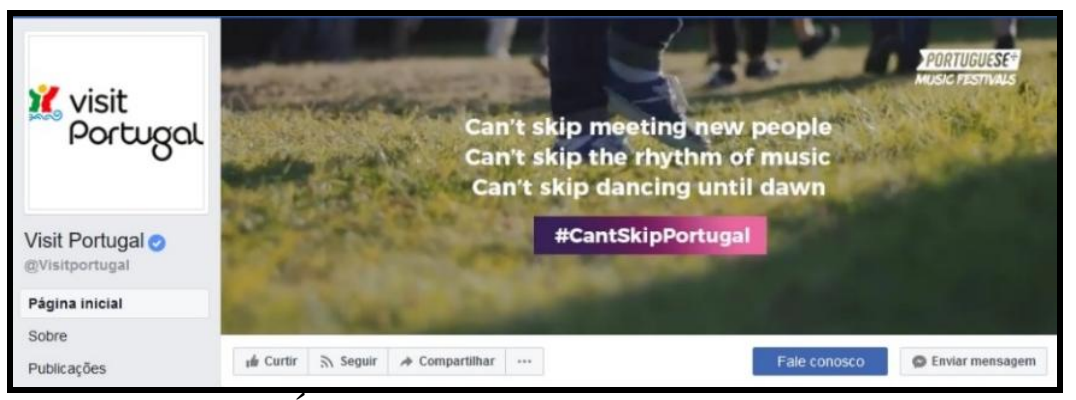

IMAGEM 5 - A PÁGINA VISIT PORTUGAL QUE POSSUI MAIS DE 1 MILHÃO DE CURTIDAS NO FACEBOOK

FONTE: Print screen retirado da página do Facebook Visit Portugal (2017).

Através desta fan page, a organização (TP) divulga informações e interage (IMAGEM 6) com os usuários da rede, visitantes e potenciais visitantes, estabelecendo mais um importante ponto de contato que permite uma relação mais horizontal e proximidade suficiente para entender as necessidades e desejos do seu público-alvo. 


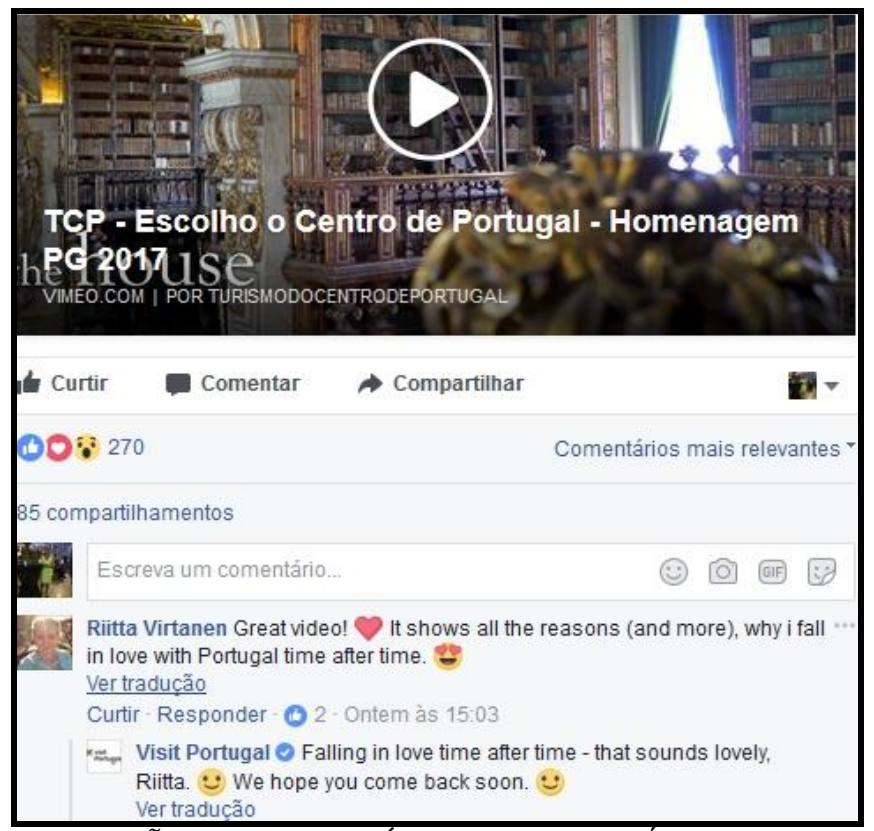

IMAGEM 6 - INTERAÇÃO COM O PÚBLICO ATRAVÉS DA SUA PÁGINA "VISIT PORTUGAL" NO FACEBOOK.

FONTE: Print screen retirado da página do facebook Visit Portugal (2017).

Quatro anos depois, em 2017, a página possuía mais de 1 milhão de seguidores (FACEBOOK, s.d.). Para além das visitas virtuais, o país alcançou sucessivos recordes de visitantes estrangeiros de 2014 a 2016 (INE, 2014, 2015, 2016, 2017); 9,4 milhões, 10,1 milhões, 11,4 milhões, 12,8 milhões. Além disso, o setor experimentou resultados quantitativos expressivos e uma massiva presença midiática sem precedentes (TP, 2014). Esses números sugerem não somente o sucesso das estratégias, mas representam o ganho de espaço e o aumento da competitividade no mercado global.

\section{CONSIDERAÇÕES FINAIS}

O presente trabalho teve como objetivo conhecer mais sobre a aplicação das mídias digitais, especialmente as Redes Sociais, para então construir hipóteses sobre a contribuição dessas ferramentas no aumento da competitividade de um determinado destino, no caso: Portugal. Foi também discutida a mudança provocada pelas redes sociais na maneira de pensar o marketing dos destinos e a competitividade.

O contexto atual do turismo se caracteriza por uma situação em que a competitividade de um destino é cada vez mais imperativa para economias dependentes da atividade turística. A revolução digital também mudou profundamente o setor de 
turismo. Com efeito, a generalização do acesso à internet, a popularização das mídias sociais e outras ferramentas inovadoras acirraram a competitividade global.

Pôde ser observado que os aspectos e elementos da estratégia de marketing digital estão presentes: nos modelos de competitividade de Crouch e Ritchie (1999), se considerar estes como recursos da organização promotora do destino; no modelo da OCDE (DUPEYRAS; MACCALLUM, 2013) que atribui imensa importância as TICs, sobretudo aos negócios digitais para o desenvolvimento do turismo, e; especialmente no modelo TTCI do Fórum Econômico Mundial (TTCI, 2017) que estão diretamente relacionados à temática da competitividade de destinos turísticos, pois estes elementos participam diretamente das diretrizes metas e planos do desenvolvimento do próprio destino, sendo base para nortear a estratégia do destino turístico.

O Turismo de Portugal elegeu as redes sociais como a base para as estratégias de enfrentamento aos atuais desafios e oportunidades do setor, cada vez mais competitivo, intensificados pela evolução das TICs (CROUCH, 2007; KAPLAN; HAENLEIN, 2010; KIRALOVA; PAVLÍČEKA, 2014; POPESCU; ALECSA, 2015; SILVA; MENDES FILHO, 2016). Essa aposta nas redes sociais também teve como mote a busca por eficiência e eficácia na utilização dos recursos, bem como se conectar com os novos perfis comportamentais dos turistas (COX et al., 2009; LANGE-FARIA; ELLIOT, 2012; HAYS; PAGE; BUHALIS, 2013; KIRALOVA; PAVLÍČEKA, 2014; POPESCU; ALECSA 2015), que permitiu superar as limitações financeiras e obter um alcance significativo de público.

Destaca-se que a presença nas redes sociais, de forma pró-ativa, parece ter sido decisiva para aumentar a visibilidade do país, desenvolver sua marca, posicionar o destino na mente dos turistas, se comunicar com a forma e conteúdo adequado a cada segmento-alvo, e, participar das etapas do processo de viagem de maneira a influenciar a escolha dos turistas. Se é por meio das práticas comunicacionais que o turista conhece um destino ou é influenciado na tomada de decisão, portanto, a forma como são utilizados os canais de promoção e venda, articulados com uma estrategia efetiva, podem ser determinantes para atrai-lo. E se o processo de comunicação de um determinado destino turístico é de fato peça-chave para a competitividade deste, por ser capaz de aumentar a compreensão sobre a o mesmo e possibilitar ao turista conhecer o destino e trocar informações e conhecimentos, aperfeiçoando tanto o serviço prestado 
como adequando a expectativa destes com a experiência turística (LODA; COLEMN, 2005; MARCHIORI; PAVESE; CANTONI, 2012), as mídias sociais constituem-se como uma ferramenta que potencializa ainda mais todo este fenômeno.

Mais que um meio de comunicação, as redes sociais são um repositório de dados e informações sobre as preferências, comportamentos, expectativas e atitudes dos indivíduos que permite que as organizações promotoras dos destinos extraiam inputs valiosos para elaboração de estrategias competitivas. Portugal foi hábil na utilização das rede sociais e suas virtudes, como destacam alguns autores (KAPLAN; HAENLEIN, 2010; YADAV; ARORA, 2012; LANGE-FARIA; ELLIOT, 2012; JUCAN; JUCAN; ROTARIU, 2013; POPESKU, 2014; KIRALOVA; PAVLÍČEKA, 2014)., seja para interação com os visitantes, disseminando suas mensagens e fortalecendo a marca, seja na coleta de dados que permitiu o ajuste de ações estratégias com base nas expectativas e desejos do seu público. Resultado foi que o destino alcançou grande popularidade, nas redes sociais e na mente das pessoas.

Portanto, parece seguro considerar que as estratégias de marketing digital nas redes sociais implementadas pelo destino Portugal estejam ligadas aos indicadores do TTCI - Country Brand Strategy rating, Effectiveness of marketing and branding to attract tourist Comprehensiveness of annual T\&T data, Cultural and entertainment tourism digital demand, Natural tourism digital demand, Mobile network coverage. E o seu sucesso, pode levar a reconhecer que tiveram impacto fundamental na mensuração destes e consequentemente elevar seu nível de competitividade.

Considerando os números alcançados (em quantidade de turistas, balança comercial, voos, acomodações, fãs e seguidores de seus perfis nas redes sociais) e seu desempenho no ranking de competitividade do Word Economic Forum desde a implementação dessa nova abordagem fundamentada nas mídias sociais, encontra-se alguma pista para considerar que Portugal parece ter colaborado para elevar seu nível de competitividade. Essas estratégias estão diretamente ligadas aos indicadores do TTCI Country Brand Strategy rating, Effectiveness of marketing and branding to attract tourist Comprehensiveness of annual T\&T data, Cultural and entertainment tourism digital demand, Natural tourism digital demand, Mobile network coverage. Porém, ainda não é possível afirmar que as estratégias de promoção com base nas redes sociais sejam decisivas para a competitividade do destino. 
O sucesso da atividade turística e a competitividade de um país ou destino não podem ser analisados de forma isolada, uma vez que está diretamente relacionado ao desempenho de organizações e de múltiplos fatores (CROUCH; RITCHIE 1999; CROUTCH, 2007), por tanto esta é apenas uma hipótese, assim como também não é possível determinar a extensão dessa influência.

Considerando que o construto competitividade não pode ser desvinculado de suas principais características, que são a relatividade e a multidimensionalidade, conforme apontam Crouch e Ritchie (1999), é preciso refletir se está sendo comparada a estratégia de utilização das redes sociais às que envolvem os meios tradicionais de mídia ou outros meios digitais, ou se está sendo comparada a forma como Portugal faz uso desses recursos em relação aos outros países. Deriva dessas características também questionamentos a respeito de quais critérios são levados em consideração para determinar o melhor desempenho no uso das mídias sociais, assim também como em que dimensão ela deve ser agrupada, se marketing, tecnologia etc.

Encontrar medida única para refletir isso requer mais trabalho $\mathrm{e}$ acompanhamento da influência das midias digitais nas perspectivas da oferta e da demanda. Não obstante os resultados não tornem explícitas as relações de causa e efeito entre as estratégias com base nas mídias digitais e a competitividade, talvez seja possível por meio de estudos mais aprofundados estabelecer correlações entre esses construtos que permitam especular e fazer inferências.

\section{REFERÊNCIAS}

BANCO DE DESENVOLVIMENTO DE PORTUGAL-BdP, Estudo da Central de Balanços - Análise do Setor do Turismo 2011-2016. Disponível em: $<$ https://www.ine.pt/xportal/xmain?xpid=INE\&xpgid=ine_publicacoes\&PUBLICACO ESpub_boui=277048338\&PUBLICACOESmodo=2>. Acesso em: 15/07/2017.

BANCO PORTUGUÊS DE INVESTIMENTO - BPI. Evolução do Turismo Nacional. Portugal, 2016. Disponível em:

<http://www.bancobpi.pt/nocachecontent/conn/UCM/uuid/dDocName:PR_WCS01_UC M01031805>. Acesso em: 15/07/2017.

BARNEY, J. B. Looking inside for the competitive. The Academy of Management Executive. 9 (4), 1995, p. 49-61. 
BUHALIS, D. Marketing the competitive destination of the future. [Eletronic Version] Tourism Management, n. 21, p. 97-116, 2000.

- Strategic use of Information Technologies in the tourism industry. In: PAPATHEODOROU, A., (ed.), Managing Tourism Destinations, Edward Elgar, Cheltenham, 2006, p. 409-421.

COX, C.; BURGESS, S.; SELLITTO, C.; BUULTJENS, J. The role of user-generated content in tourists' travel planning behaviour. Journal of Hospitality Marketing \& Management, 18 (8), 2009, p. 743-764.

CRESWELL, J. W. Projeto de pesquisa: métodos qualitativo, quantitativo e misto. 2 ed. Porto Alegre: Artmed, 2007.

CROUCH, G. I.; RITCHIE, J. R. B. Tourism, Competitiveness, and Societal Prosperity. Journal of business research, v. 44, n. 3, 1999, p. 137-152.

CROUCH, G. I. Modelling Destination Competitiveness: A Survey and Analysis of the Impact of Competitiveness Attributes, CRC for Sustainable Tourism Pty Ltd, Queensland, Australia. 2007.

Destination Competitiveness: An Analysis of Determinant Attributes. Journal of Travel research, SAGE Publications, 50 (1), 2011, p. 27-45.

CRUZ, V. L. L.; MOTA, K. M.; PERINOTTO, A. R. C. Redes Sociais na Internet: Estratégia para Divulgação das Potencialidades Turísticas do Piauí - Brasil. [Versão Eletrônica] Revista Rosa dos Ventos, 4 (I), jan.-jun., 2012, p. 77-88.

DUPEYRAS, A; MACCALLUM, N. Indicators for Measuring Competitiveness in Tourism: A Guidance Document, OECD Tourism Papers, 2013/02, OECD Publishing.

FIGUEIREDO, J. C. de. Turismo de Portugal reduz custos de promoção e aumenta visibilidade do destino. Publituris. Portugal, 2 jun. 2014. Entrevista.

. Os segredos que puseram Portugal no mapa do turismo. Público. Portugal. 04 mar. 2017. Entrevista. 2017a.

Turismo: O segredo do nosso sucesso. Expresso. Portugal, 17 jun. 2017 Entrevista. 2017b.

GOOGLE, YEAR IN SEARCH 2016. Disponível em: <https://trends.google.com/trends/yis/2016/GLOBAL/>. Acesso em: 11/07/2017.

GOOROOCHURN, N.; SUGIYARTO, G. Competitiveness Indicators in Travel and Tourism Industry, Tourism Economics, 11 (1), 2005, p. 25-43. 
HAYS, S.; PAGE, S. J.; BUHALIS, D. Social media as a destination marketing tool: its use by national tourism organisations, Current Issues in Tourism, 16 (3), 2013, p. 211-239, DOI: 10.1080/13683500.2012.662215

INSTITUTO NACIONAL DE ESTATÍSTICA (INE), Estatísticas do Turismo. Lisboa, Portugal 2014-2017.

JUCAN, M.; JUCAN, C.; ROTARIU, I. The Social Destination: How Social Media Influences the Organisational Structure and Leadership of DMOs, World Academy of Science, Engineering and Technology, 78, 2013, p. 1426-1432.

KAPLAN, A. M.; HAENLEIN, M. Users of the world, unite! The challenges and opportunities of Social Media. Business Horizons, 53 (1), 2010, p. 59-68.

KIRÁlOVA, A.; PAVLICEKA, A. Development of Social Media Strategies. In: Tourism Destination. Procedia: Social and Behavioral Sciences, 175, p. 358-366. Disponível em:

<http://www.sciencedirect.com/science/article/pii/S1877042815012719\#>. Acesso em: $11 / 08 / 2017$.

LANGE-FARIA, W.; ELLIOT, S. Understanding the role of social media in destination marketing, Tourismos, 7 (1), 2011, p. 193-211.

LODA , M. D.; COLEMAN . B. C. Sequence Matters: A More Effective way to Use Advertising and Publicity. Journal of Advertising Research, v. 45 n. 4, 2005, p. 362372.

LIMA, A. P. de. Turismo de Portugal reduz custos de promoção e aumenta visibilidade do destino. Publituris. Portugal, 2 jun. 2014. Entrevista.

MARCHIORI, E. ; PAVESE, G. ; CANTONI, L. eTcoMM-eTourism communication maturity model. A framework to evaluate the maturity of a DMO when it comes to the online communication management: The case of Canton Ticino and Lombardy. Springer. Information and Communication Technologies in Tourism. Jan, 2012 p. 24-27. Disponível em: <https://link.springer.com/chapter/10.1007/978-3-7091-11420_19 >. Acesso em: 09/06/2017.

MAZANEC, J. A.; WÖBER, K.; ZINS, A. H. Tourism destination competitiveness: from definition to explanation, Journal of Travel Research, 46, 2007, p. 86-95.

MONTEIRO, L. Os segredos que puseram Portugal no mapa do turismo. Público. Portugal. 04 mar. 2017. Entrevista. 2017a.

NUNES, A. M.. Os segredos que puseram Portugal no mapa do turismo. Público. Portugal. 04 mar. 2017. Entrevista. 2017a.

POPESKU, S. Social media as a tool of destination marketing organizations. EBusiness in Tourism and Hospitality Industry. Sinteza. 2014, p. 715-721. 
POPESCU, F.; ALECSA, I. C. Gaining competitive advantage using social media. Longer allows Romanian rural tourism industry to ignore presence on social media? In: PROCEEDINGS OF THE INTERNATIONAL MANAGEMENT CONFERENCE. 2015, Bucharest, Romania. Anais... Bucharest: ASE, 2015. p. 513-522.

SILVA, J. C.; MENDES FILHO, L. A influência das tecnologias da informação e comunicação nos destinos turísticos inteligentes. In: SEMINÁRIO DE PESQUISA DO CENTRO DE CIÊNCIAS SOCIAIS APLICADAS (CCSA/UFRN), 21., 2016, Natal. Anais... Natal: Centro de Ciências Sociais Aplicadas (CCSA/UFRN), 2016.

TURISMO DE PORTUGAL. Plano Estratégico Nacional do Turismo. Horizonte 2006-2015. Lisboa, Portugal. 2007.

Plano Estratégico Nacional do Turismo. Horizonte 2013-2015. Disponível em: <http://www.turismodeportugal.pt/PORTUGU\%C3\%8AS/TURISMODEPORTUGAL/ PUBLICACOES/Documents/PENT\%202012.pdf>. Acesso em: 11/06/2017.

Plano de Ação para o Desenvolvimento do Turismo em Portugal 2020. Lisboa, Portugal. 2014a. Disponível em:

$<$ http://estrategia.turismodeportugal.pt/sites/default/files/Turismo2020_Parte\%20I_merc ados\%20-\%20SWOT.pdf $>$. Acesso em: 11/06/2017.

A comunicação do destino Portugal: A ascensão do online. Lisboa, Portugal. 2007. 2014b. Disponível em:

<http://www.turismodeportugal.pt/PORTUGU\%C3\%8AS/TURISMODEPORTUGAL/ APRESENTACOES/Documents/A\%20Comunicacao\%20do\%20Destino\%20Portugal\% 2002062014.pdf>. Acesso em: 11/06/2017.

WORLD ECONOMIC FORUM (WEF). The Travel and Tourism Competitiveness Report 2013, Disponível em:

<www3.weforum.org/docs/TT15/WEF_Global_Travel\&Tourism_Report_2015.pdf>.

Acesso em: 12/04/2017.

The Travel and Tourism Competitiveness Report 2015. Disponível em: <www3.weforum.org/docs/TT15/WEF_Global_Travel\&Tourism_Report_2015.pdf>. Acesso em: 12/04/2017.

The Travel and Tourism Competitiveness Report 2017, Disponível em: <www3.weforum.org/docs/TT15/WEF_Global_Travel\&Tourism_Report_2015.pdf>. Acesso em: 12/04/2017.

YADAV, V.; ARORA, M. The Product Purchase Intentions in Facebook Using Analytical Hierarchical Process. Radix International Journal of Economics and Business Management, 1 (4), 2012, p. 26-54. Acesso em: 02/06/2017.

Recebido em: 31-08-2017.

Aprovado em: 30-09-2017. 